\title{
Polythionate formation during uranium recovery from sulphide flotation concentrate
}

\author{
by V. Yahorava and V. Bazhko
}

\section{Synopsis}

Uranium recovery by resin-in-pulp (RIP) from sulphide-bearing material was found to be adversely affected by polythionate formation due to partial oxidation of sulphide minerals. Polythionates are loaded more selectively by the conventional strong-base resins used at uranium plants.

A study was undertaken to identify whether polythionates are formed during upstream processing, leaching, or ion exchange recovery steps. It was found that polythionate formation could be minimized by shortening of the leach time, optimizing oxidant and acid addition, minimizing delay between leaching and RIP, and maintaining the neutralization and adsorption retention times as short as possible.

These insights could prompt the development of mitigation strategies on commercial plants to reduce or avoid the formation of polythionates and the adverse impact it has on uranium recovery.

Keywords

uranium recovery, resin-in-pulp, polythionate formation.

\section{Introduction}

South Africa has approximately 320000 ha of surface area covered by gold tailing dumps containing $0.2-0.4 \mathrm{~g} / \mathrm{t}$ gold and up to $0.7 \%$ sulphides as well as around $100 \mathrm{~g} / \mathrm{t}$ uranium. During the boom in uranium prices around 2007, the re-processing of dumps at gold mines for both gold and uranium recovery became economically attractive. A number of flow sheets were developed, all of which included flotation of a sulphide concentrate followed by uranium leaching and removal via ion exchange prior to gold recovery (Fleming, Brown, and Botha, 2010; van Rensburg and Mashaba, 2016).

The flotation concentrates generated through re-processing of gold dumps typically contain 100 to $900 \mathrm{mg} / \mathrm{kg}$ uranium oxide $\left(\mathrm{U}_{3} \mathrm{O}_{8}\right)$ (van Rensburg and Mashaba, 2016; van Tonder and Kotze, 2007; Fleming, Brown, and Botha, 2010). RIP technology is often considered for the recovery of uranium from the low-grade slurries $\left(<900 \mathrm{mg} / \mathrm{L} \mathrm{U}_{3} \mathrm{O}_{8}\right)$ due to the cost benefit associated with elimination of the solid/liquid separation step.

In recent years a number of cases have been observed in the Mintek laboratories where unexpectedly low uranium loadings onto the resin were achieved during RIP tests.

* Mintek, Randburg, South Africa.

(C) The Southern African Institute of Mining and Metallurgy, 2018. ISSN 2225-6253. This paper was first presented at the Uranium 2017 International Conference, 12-13 September 2017, Swakopmund Hotel, Swakopmund, Namibia.. 


\section{Polythionate formation during uranium recovery from sulphide flotation concentrate}

$\mathrm{pH}$ adjustment of the leach slurry was conducted either at ambient temperature or at $50^{\circ} \mathrm{C}$ by addition of $20 \%(\mathrm{~m} / \mathrm{m})$ lime $\left(\mathrm{Ca}(\mathrm{OH})_{2}\right)$ slurry. The $\mathrm{pH}$ was adjusted to either 3 or 3.5-3.8, depending on the case studied.

\section{Resin preparation}

Purolite A500/2788 RIP-grade strong-base type I resin was used for the test work. In cases 1 and 2 the resin in sulphate form was pre-fouled with silica up to approximately $15 \%$ $\mathrm{SiO}_{2}$ by two cycles of contact with a freshly-prepared $3 \mathrm{~g} / \mathrm{L}$ silica $\left(\mathrm{SiO}_{2}\right)$ solution at $\mathrm{pH} 1$ for 24 hours in rolling bottles at a solution-to-resin ratio of 10 to 1 . At the end of each cycle, the resin was washed with deionized water.

In case 3 the resin was used 'as is' after conversion into the sulphate form by passing four bed volumes (BVs) of $1 \mathrm{M}$ $\mathrm{H}_{2} \mathrm{SO}_{4}$ through the resin bed at a flow rate of $2 \mathrm{BV} / \mathrm{h}$. After contact with the acid, the resin was washed with deionized water until the water exited the column at $\mathrm{pH} 2$.

\section{Resin-in-pulp equilibrium isotherms}

Equilibrium adsorption isotherms were generated by batch contacting the pretreated resin and the pulp at different contact ratios over 24 hours at ambient temperature. The resins were separated from the pulp using a $600 \mu \mathrm{m}$ screen. The pulp was filtered and the solids repulped (water-to-wet solids mass ratio of 2:1) and then washed (at a mass ratio of 1:1) using $\mathrm{pH}$ - adjusted deionized water ( $\mathrm{pH}$ of the wash water was adjusted to 3.5).

The resin removed from each equilibrium contact was washed with deionized water to remove entrained solids and solution and was then either eluted with $30 \mathrm{BVs}$ of $2 \mathrm{M}$ nitric acid (HNO3) and 25 BVs of $1 \mathrm{M}$ sodium hydroxide $(\mathrm{NaOH})$ or dried and analysed directly for uranium and other impurities.

\section{Analysis}

Depending on the focus and level of detail required, either ICP-OES/ICP-MS or XRF was used for the analysis of base metals and uranium in solution and solids.

\section{Table I}

Samples for test work

\begin{tabular}{|l|c|c|c|}
\hline Sample & $\mathbf{S}, \%$ & $\mathbf{U}_{\mathbf{3}} \mathbf{O}_{\mathbf{8}}, \mathbf{~} \mathbf{m g} \mathbf{k g}$ & Fraction $\mathbf{- 3 8} \boldsymbol{\mu m}, \mathbf{\%}$ \\
\hline Sample 1 & $10-15$ & 136 & 43 \\
Sample 2 & $25-30$ & 213 & 63 \\
Sample 3 & 1.52 & 195 & 48 \\
Sample 4 & 6.19 & 96 & 90 \\
\hline
\end{tabular}

\section{Results and discussion}

Four different samples of flotation concentrates were used in the study, their uranium and sulphide contents are provided in Table I.

\section{Case 1: High sulphide content}

\section{Problem identification}

Two flotation concentrates, produced during a mini-pilot plant campaign conducted by Mintek at a South African gold mine, were received and were labelled sample 1 and sample 2 . The samples were air-dried prior to being prescreened and blended in preparation for the test work.

Leaching of both samples resulted in approximately $80 \%$ $\mathrm{U}_{3} \mathrm{O}_{8}$ extraction into solution. The pregnant leach solution (PLS) composition is provided in Table II. The pH was controlled between 1.5 and 1.7; no oxidant was added and the Eh ranged naturally between 414 and $422 \mathrm{mV}$ (Ag/AgCl).

After 24 hours of leaching, the pH of the pulp was adjusted to 3 by the addition of lime as dry powder over 3 hours prior to the ion exchange tests, which were conducted within about 1 hour of $\mathrm{pH}$ adjustment.

The uranium equilibrium adsorption isotherms obtained with Purolite A500 resin at pH 3 are presented in Figure 1.

The 'displacement' shape of the equilibrium isotherms (particularly pronounced for sample 2 ) indicated the presence of species that adsorbed more selectively than uranium and hence displaced uranium from the resin at higher pulp-toresin ratios. A detailed investigation of potential competing ions in the leach liquors then followed, whereby the presence of such anions as nitrates, chlorides, and phosphates was ruled out.

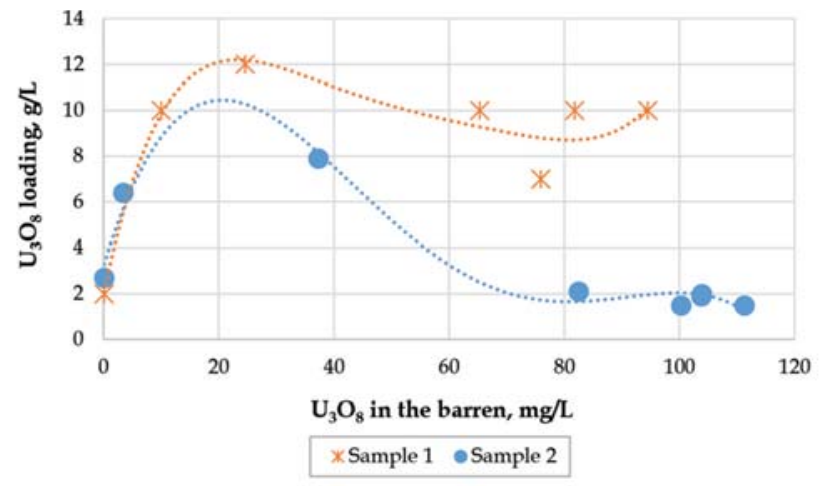

Figure 1-Uranium equilibrium adsorption isotherms: samples 1 and 2, pH 3

Table II

PLS composition for samples 1 and 2, $\mathrm{mg} / \mathrm{L}$

\begin{tabular}{|c|c|c|c|c|c|c|c|c|c|c|c|c|c|}
\hline Sample & $\mathrm{Mg}$ & Al & $\mathrm{SiO}_{2}$ & $\mathrm{Ca}$ & Mn & $\mathrm{Fe}$ & Co & $\mathrm{Ni}$ & $\mathrm{Cu}$ & $\mathrm{Zn}$ & $S, g / L$ & As & $\mathrm{U}_{3} \mathrm{O}_{8}$ \\
\hline 1 & 928 & 964 & 3062 & 495 & 235 & 7410 & 47 & 169 & 72 & 90 & 11 & 104 & 124 \\
\hline 2 & 762 & 868 & 2640 & 510 & 211 & 7950 & 62 & 213 & 81 & 91 & 10 & 127 & 140 \\
\hline $1^{*}$ & 837 & 1160 & 1090 & 459 & 292 & 7250 & 25 & 115 & 57 & 148 & 9.7 & 74 & 207 \\
\hline
\end{tabular}




\section{Polythionate formation during uranium recovery from sulphide flotation concentrate}

The main characteristic of the samples evaluated during case 1 was the high concentration of sulphides $(10-15 \%$ for sample 1 and $25-30 \%$ S2- for sample 2). Unexpectedly, sulphur was detected in caustic eluates produced during silica stripping with $\mathrm{HNO}_{3}$ after uranium elution. This suggested the presence of sulphur species like polythionates as the reason for the poor uranium adsorption of the anion exchange resin. Polythionates $\left(\mathrm{S}_{n} \mathrm{O}_{6}{ }^{2-}\right.$ where $\left.n>3\right)$ are known to be strong competitors for the exchange sites of the resin and can be eluted from the resin by treatment with caustic solution (Schmiedel, 1984).

\section{Formation of polythionates: some theory}

Polythionates can be produced during leaching, milling, and flotation of materials that are rich in sulphides (Vongprom, Hawboldt,and Bottaro, 2008; Rempel and Chanda, 1986).

During oxidative leaching of uranium-containing material, dissolution/oxidation of pyrite occurs and can be described by the following equations:

$$
\begin{aligned}
& 2 \mathrm{FeS}_{2}+7 \mathrm{O}_{2}+2 \mathrm{H}_{2} \rightarrow \\
& 2 \mathrm{Fe}^{2+}+4 \mathrm{H}^{+}+4 \mathrm{SO}_{4}^{2-} \\
& \mathrm{FeS}_{2}+15 / 4 \mathrm{O}_{2}+7 / 2 \mathrm{H}_{2} \mathrm{O} \rightarrow \\
& \mathrm{Fe}(\mathrm{OH})_{3}+2 \mathrm{SO}_{4}^{2-}+4 \mathrm{H}^{+} \\
& \mathrm{FeS}_{2}+14 \mathrm{Fe}^{3+}+8 \mathrm{H}_{2} \mathrm{O} \rightarrow \\
& 15 \mathrm{Fe}^{2+}+2 \mathrm{SO}_{4}^{2-}+16 \mathrm{H}^{+}
\end{aligned}
$$

The oxidation of sulphur results in the formation of sulphate, $\mathrm{SO}_{4}{ }^{2-}$ as a final product. However, it has been shown by a number of researchers (Druschel and Borda, 2006; Descostes, Vitorge, and Beaucaire, 2004) that metastable sulphur species can be formed by $\mathrm{FeS}_{2}$ oxidation;

$$
\begin{aligned}
& \mathrm{FeS}_{2}+3 / 2 \mathrm{O}_{2} \rightarrow \mathrm{Fe}^{2+}+\mathrm{S}_{2} \mathrm{O}_{3}^{2-} \\
& \mathrm{S}_{2} \mathrm{O}_{3}^{2-}+6 / 5 \mathrm{H}^{+} \rightarrow 2 / 5 \mathrm{~S}^{0}+ \\
& 2 / 5 \mathrm{~S}_{4} \mathrm{O}_{6}^{2-}+3 / 5 \mathrm{H}_{2} \mathrm{O} \\
& \mathrm{S}_{x} \mathrm{O}_{6}^{2-}+\mathrm{S}_{2} \mathrm{O}_{3}^{2-} \rightarrow 7 \mathrm{~S}_{x+1} \mathrm{O}_{6}^{2-}+\mathrm{SO}_{3}^{2-} \\
& 8 \mathrm{~S}_{2} \mathrm{O}_{3}^{2-}+\mathrm{H}^{+} \rightarrow \mathrm{S}_{8}+7 \mathrm{SO}_{3}^{2-}+\mathrm{HSO}_{3}^{-}
\end{aligned}
$$

The formation of polythionates depends on leaching conditions (Lowson, 1982; McKay and Halpern, 1958; Woodcock, 1961). Tetrathionate formation has been reported as a product of pyrite oxidation at $\mathrm{pH}$ 2.9-8.6 in the presence of molecular oxygen, at $\mathrm{pH} 8$ in the presence of $\mathrm{MnO}_{2}$, and at $\mathrm{pH} 2$ in the presence of $\mathrm{Fe}$ (III) (Schippers, 2004). Other sources state that in order to minimize formation of polythionates during leaching, it is necessary to maintain the acid concentration at greater than $5 \mathrm{~g} / \mathrm{L} \mathrm{H}_{2} \mathrm{SO}_{4}$ (Nugent, 1956; Druschel and Borda, 2006). Under these conditions the polythionate concentrations were reported to be in the order of $20-30 \mathrm{mg} / \mathrm{L} \mathrm{S}$ and not to constitute a serious problem. Should the acid concentration during leaching drop to a value $\leq 1 \mathrm{~g} / \mathrm{L}$ for a period of an hour, polythionates exceeding $100 \mathrm{mg} / \mathrm{L} \mathrm{S}$ can be formed, with serious consequences for the ion exchange process.
The degradation of polythionate strongly depends on $\mathrm{pH}$ and on the availability of catalysts such as pyrite and heavy metals. It has been reported that the overall rate of polythionate oxidation is markedly slower than the rate of oxidation of thiosulphate (forming polythionate) in acidic, ferric-rich solutions (Druschel, Hamers, and Banfield, 2003). In contrast, polythionate degrades at low $\mathrm{pH}$ in the presence of sulphide $\left(\mathrm{FeS}_{2}\right)$ (Schippers, 2004).

In summary, it is suggested that polythionates can be formed during:

> Mineral processing ahead of leaching (comminution, flotation, drying)

$>$ Leaching at $\mathrm{pH} 1.5-1.8$

$>$ During the relatively long time intervals between leaching, neutralization, and the resin contacts, or during RIP (which was run over 24 hours).

\section{Mitigation strategies for uranium recovery}

The first mitigation strategy evaluated was polythionate destruction by Eh adjustment to $500 \mathrm{mV}(\mathrm{Ag} / \mathrm{AgCl})$ at $\mathrm{pH}$ 3.0-3.5. Hydrogen peroxide and lime were used as oxidant and neutralizing reagents respectively, and the procedure was tested on aged leach slurry of sample 2 (exhibiting the highest sulphide content). The uranium loading achieved at high pulp-to-resin ratio improved from $1.3 \mathrm{~g} / \mathrm{L}$ from the slurry 'as is' (Eh $280 \mathrm{mV}, \mathrm{pH} 3.5$ ) to $26.2 \mathrm{~g} / \mathrm{L}$ from the preoxidized sample (Eh $500 \mathrm{mV}, \mathrm{pH} 3.5$ ). This suggests that the species (suspected to be polythionates) competing with uranium for the ion exchange adsorption sites was destroyed by oxidation. The final barren concentrations achieved were similar, i.e. 119 and $100 \mathrm{mg} / \mathrm{L} \mathrm{U}_{3} \mathrm{O}_{8}$ respectively. However, the oxidation of polythionates might not be attractive economically due to the increased OPEX associated with the reagent costs.

The second strategy evaluated was replacement of the strong-base resin (with high affinity for polythionates) with a chelating resin that is not selective to anionic species. RIP tests were conducted using RIP-grade iminodiacetic Purolite S930 resin. The pulp generated during the leaching of sample 2 was used for these RIP tests, with the pH controlled at 3.5 by addition of sodium hydroxide $(\mathrm{NaOH})$. The equilibrium adsorption isotherm generated is presented in Figure 2, together with the isotherm obtained for the same pulp with the strong-base Purolite A500 resin for comparison.

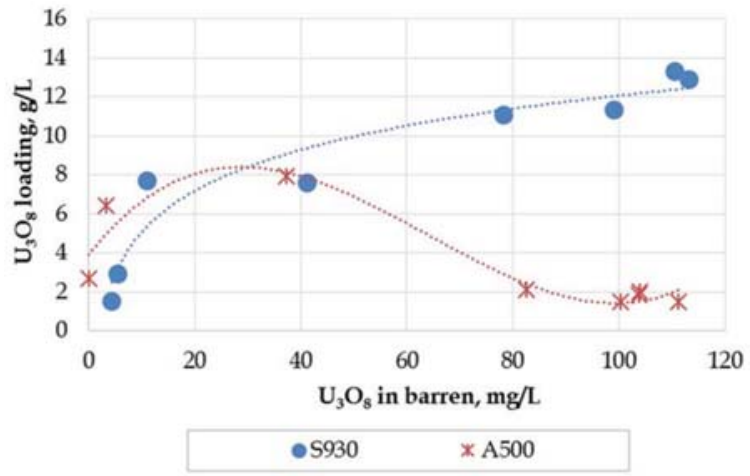

Figure 2-Uranium recovery from polythionate-bearing pulp by strongbase (A500) and chelating (S930) resins at pH 3.5 


\section{Polythionate formation during uranium recovery from sulphide flotation concentrate}

The iminodiacetic resin recovered uranium more efficiently from polythionate-bearing pulp than the strongbase resin, although high co-loadings of base metals like aluminium, copper, iron, nickel, and zinc were observed. Selective elution or additional purification steps will therefore be required for downstream processing of the uranium eluate if this resin is used for uranium recovery from polythionatebearing pulp.

The prevention of pyrite oxidation (which initiates the formation of the intermediate sulphur species appearing in Equations 4 to 7 prior to, during, and after leaching) is likely to be an economically attractive option. This concept was tested using a flotation concentrate (with 10-15\% sulphide content) that had been kept 'fresh' at the mine by storage under water. The sample was leached at pH 1.8 over 8 hours with mild agitation of the slurry to minimize oxygen ingress, which could lead to sulphide oxidation. The composition of the leach liquor obtained appears in Table II; the final Eh was $422 \mathrm{mV}$ (Ag/AgCl). The slurry was neutralized to $\mathrm{pH} 3.5$ immediately and subjected to ion exchange test work with resin pre-fouled with approximately $12.5 \% \mathrm{SiO}_{2}$.

The equilibrium adsorption isotherms are shown in Figure 3.

An equilibrium loading of approximately $25 \mathrm{~g} / \mathrm{L} \mathrm{U}_{3} \mathrm{O}_{8}$ was achieved at a barren concentration of approximately $80 \mathrm{mg} / \mathrm{L} \mathrm{U}_{3} \mathrm{O}_{8}$ in solution, which is much improved compared to the loading of approximately $10 \mathrm{~g} / \mathrm{L}$ obtained from the aged sample 1 at a barren concentration of $80 \mathrm{mg} / \mathrm{L} \mathrm{U}_{3} \mathrm{O}_{8}$ in solution.

The strategy of minimizing sulphide oxidation and ageing of the samples was found to be successful in minimizing the presence of species competing with uranium for resin sites, yielding more typical uranium loadings.

\section{Case 2: Low sulphide content}

\section{Problem identification}

Sample 3 is a flotation concentrate blended with slimes to contain $1.52 \% \mathrm{~S} 2-$ and $195 \mathrm{mg} / \mathrm{kg}$ uranium. Uranium leaching was conducted at $60^{\circ} \mathrm{C}$ with $\mathrm{pH}$ and Eh controlled at 1.5 and $450 \mathrm{mV}(\mathrm{Ag} / \mathrm{AgCl})$ by addition of $\mathrm{H}_{2} \mathrm{SO}_{4}$ and $\mathrm{MnO}_{2}$ respectively. The composition of the resulting leach liquor, determined immediately after the leach and after neutralization, appears in Table III.

The leach pulp was cooled and stored in a refrigerator for about one week prior to being neutralized to $\mathrm{pH} 3.0$ at ambient temperature, and then used for uranium RIP test work. Uranium adsorption was evaluated using Purolite A500 resin containing approximately $15 \% \mathrm{SiO}_{2}$, with the equilibrium adsorption isotherm appearing in Figure 4.

A slight decrease in $\mathrm{pH}$ to 2.8 was observed upon completion of the test (after 24 hours). The resin samples were analysed for uranium and base metals using XRF.
Similar to the first results obtained under case 1 on samples 1 and 2, unexpectedly low maximum uranium loadings (approx. $16 \mathrm{~g} / \mathrm{L}$ ) were achieved at high pulp-toresin ratios, and once again the presence of polythionates was suspected to be responsible.

\section{Mitigation strategies}

The following mitigating strategies were evaluated:

> Uranium leaching at 4 and 24 hours' residence time $\left(60^{\circ} \mathrm{C}, \mathrm{pH} 1.5, \mathrm{Eh}>450 \mathrm{mV}(\mathrm{Ag} / \mathrm{AgCl})\right)$, followed by neutralization to $\mathrm{pH} 3.5\left(60^{\circ} \mathrm{C}\right)$ immediately upon completion of leaching), and

> RIP contacts at three pulp-to-resin ratios (due to limited amount of sample available) immediately upon completion of neutralization.

The final leach parameters and reagent consumptions appear in Table IV. The redox potential remained at 430 $450 \mathrm{mV}(\mathrm{Ag} / \mathrm{AgCl})$ during the first 4 hours of leaching without the addition of $\mathrm{MnO}_{2}$, and only after 7 hours was an Eh adjustment with $\mathrm{MnO}_{2}$ required. The acid consumption during the 4-hour leach was almost $10 \mathrm{~kg} / \mathrm{t}$ lower than that

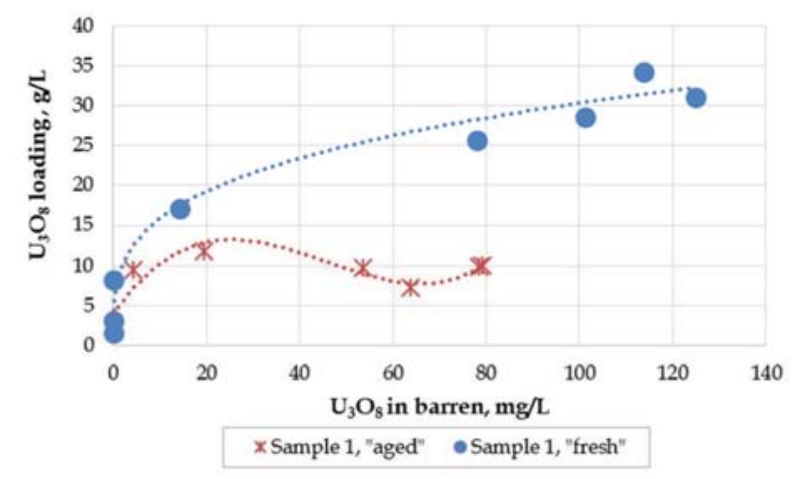

Figure 3-Uranium equilibrium isotherms from fresh and aged pulp (sample 1) by strong-base resin

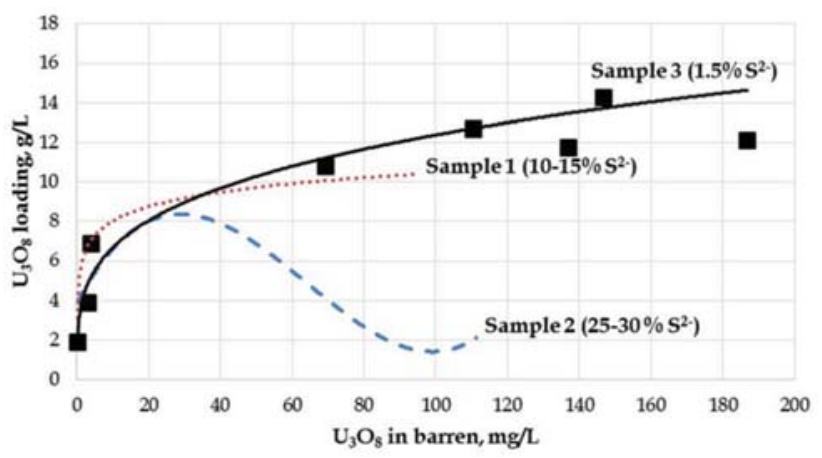

Figure 4-Uranium equilibrium isotherms from aged pulp, sample 3

\section{Table III}

PLS composition after leaching and neutralization to $\mathrm{pH} 3.0$ of sample $3, \mathrm{mg} / \mathrm{L}$

\begin{tabular}{|l|c|c|c|c|c|c|c|}
\hline & $\mathbf{M g}$ & $\mathbf{A l}$ & $\mathbf{C a}$ & $\mathbf{M n}$ & $\mathbf{F e}$ & $\mathbf{S}, \mathbf{g} / \mathbf{L}$ & $\mathbf{U}_{3} \mathbf{O}_{\mathbf{8}}$ \\
\hline After leach & 963 & 916 & 597 & 3145 & 3660 & 11.85 & 173 \\
After neutralization & 811 & 860 & 544 & 5200 & 3020 & 7.9 & 86 \\
\hline
\end{tabular}




\section{Polythionate formation during uranium recovery from sulphide flotation concentrate}

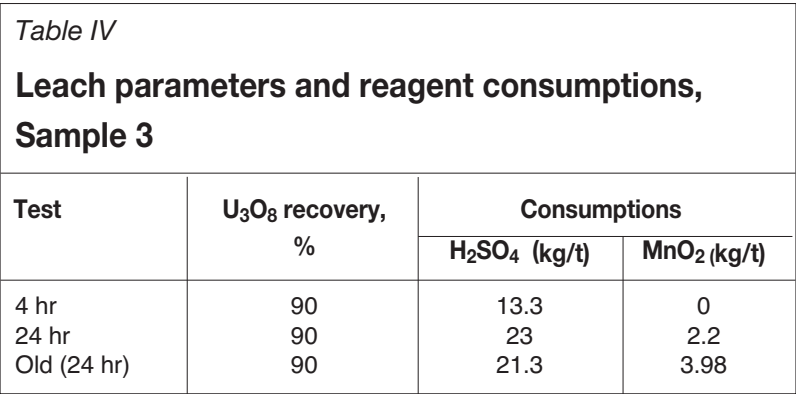

of the 24-hour leach, with no compromise in uranium extraction. Moreover, as discussed for case 1, the reduced leach residence time probably minimized sulphide oxidation with the associated formation of polythionates.

The chemical composition of the leach liquors after neutralization is shown in Table V. Significant variations in $\mathrm{Fe}, \mathrm{Mn}$, and $\mathrm{S}$ concentrations only can be seen.

Overdosing of oxidant $\left(\mathrm{MnO}_{2}\right)$ is likely to occur during relatively small-scale laboratory experiments and most probably it resulted in additional oxidation of pyrite. Thus, difference in Fe and Mn concentrations was observed.

Similar uranium loadings were observed at all three pulpto-resin contact ratios, irrespective of the leach residence time and ageing time. However, the iron co-loading reported after resin contact with fresh pulp was much lower than the results achieved on the aged pulp, as shown in Figure 5.

The sequential elution of the resin with $\mathrm{HNO}_{3}$ followed by $\mathrm{NaOH}$ revealed that the resin samples contacted with the 4-hour leach pulp did not load sulphur as polythionates ( $<5 \mathrm{mg} / \mathrm{L}$ of sulphur was determined in $\mathrm{NaOH}$ eluate), while resin contacted with the 24-hour leach slurry contained around $1 \mathrm{~g} / \mathrm{L}$ sulphur as polythionates. This confirms that an extended leach duration and/or addition of $\mathrm{MnO}_{2}$ results in the formation of sulphur species that load onto the resin.

Unfortunately, due to limited sample, adsorption tests at higher pulp-to-resin ratios were not performed.

\section{Case 3: Medium sulphide content}

A Mintek demonstration plant was operated at the Gold Fields South Deep mine in December 2016, during which sulphide- and uranium-bearing concentrate (sample 4) was produced, bearing $6.19 \%$ sulphides (as pyrite) and $96 \mathrm{mg} / \mathrm{kg}$ $\mathrm{U}_{3} \mathrm{O}_{8}$ (Olivera, 2016).

By this time, polythionate formation from sulphidebearing samples was anticipated based on the prior experience described above, and the study was tailored towards a more focused research on the polythionate phenomenon.

Sample 4 was air-dried ('aged') prior to the test work and split into two portions:

> The first portion, labelled 'aged concentrate', was subjected to uranium leaching without any pretreatment

- The second portion, labelled 'washed concentrate', was washed three times by re-pulping with deionized water (1-to-3 solids to wash water) to remove any soluble products of sulphide oxidation that might have formed during its production and preparation.

The wash waters contained detectable concentrations (>2 $\mathrm{mg} / \mathrm{L}$ ) of $\mathrm{Ca}, \mathrm{Mg}, \mathrm{Mn}$, and $\mathrm{S}$ as shown in Table VI.
Both samples were leached at $50 \% \mathrm{~m} / \mathrm{m}$ solid content, $50^{\circ} \mathrm{C}$, and $\mathrm{pH} 1.5$ for 24 hours. The redox potential was controlled at $450 \mathrm{mV}(\mathrm{Ag} / \mathrm{AgCl})$ using $\mathrm{MnO}_{2} \cdot \mathrm{MnO}_{2}$ addition was required for Eh control in both cases; however, in the case of the aged concentrate the Eh dropped after 1 hour of leaching, while in the case of the washed sample, addition of $\mathrm{MnO}_{2}$ was required only after 5 hours.

After leaching the aged and washed slurries were each split into two portions. The one portion was neutralized to $\mathrm{pH}$ 3.5 immediately using lime at $50^{\circ} \mathrm{C}$ and subjected to RIP contacts, while the other was left for a week to age before neutralization and RIP.

Analyses of the PLS from the leaching of the concentrates as well as the solution analyses after the subsequent neutralization tests (prior to RIP contacts) are shown in Table VII.

Only the iron concentrations differed significantly between the aged and washed concentrates. This suggests that iron occurred in the leach slurry of the aged concentrate mainly as ferric, which was precipitated during $\mathrm{pH}$ adjustment, while it occurred mostly as ferrous iron in the

\begin{tabular}{|l|c|c|c|}
\hline \multicolumn{3}{|l|}{ Table $V$} \\
Leach liquor composition after neutralization \\
\hline \multirow{2}{*}{ Element } & \multicolumn{3}{|c|}{ Analysis versus leach residence time (mg/L) } \\
\cline { 2 - 4 } & 4 & 24 & Old (24 h) \\
\hline $\mathrm{Ca}$ & 493 & 570 & 661 \\
$\mathrm{Co}$ & 15.5 & 16 & 22 \\
$\mathrm{Fe} 2+$ & 1465 & 76 & 3250 \\
$\mathrm{Mg}$ & 473.5 & 758 & 812 \\
$\mathrm{Mn}$ & 202 & 1510 & 5020 \\
$\mathrm{Ni}$ & 38.5 & 40 & 63 \\
$\mathrm{~S}$ & 980 & 1500 & 8200 \\
$\mathrm{Si}$ & 125 & 95 & 251 \\
$\mathrm{Zn}$ & 46.5 & 52 & 74 \\
\hline
\end{tabular}

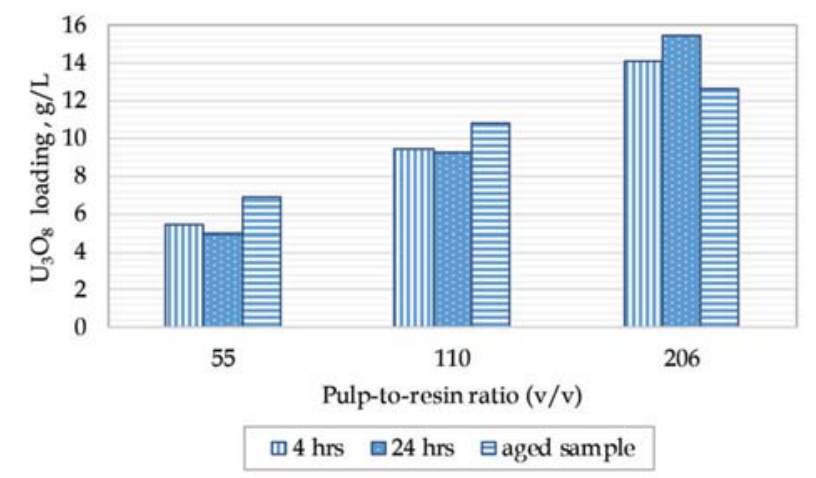

Figure 5-Uranium equilibrium loadings at similar pulp-to-resin ratios

Table VI

Wash waters analysis, $\mathrm{mg} / \mathrm{L}$

\begin{tabular}{|l|c|c|c|}
\hline Element & Wash 1 & Wash 2 & Wash 3 \\
\hline $\mathrm{Ca}$ & 457 & 214 & 76 \\
$\mathrm{Mg}$ & 31 & 15 & 6.8 \\
$\mathrm{Mn}$ & 8.85 & $<2$ & $<2$ \\
$\mathrm{~S}$ & 404.5 & 178 & 46 \\
\hline
\end{tabular}




\section{Polythionate formation during uranium recovery from sulphide flotation concentrate}

\begin{tabular}{|l|l|c|c|c|c|}
\hline $\begin{array}{l}\text { Table VII } \\
\text { Analysis of PLS before and after neutralization to } \\
\text { pH } 3.5 \text { (mg/L) }\end{array}$ \\
\hline Sample & Al & Fe & Mg & Mn & S \\
\cline { 2 - 6 } & \multicolumn{5}{|c|}{ After leach } \\
\hline Aged concentrate PLS & 1950 & 12100 & 3190 & 5690 & 24700 \\
Washed concentrate PLS & 1300 & 8250 & 2110 & 4280 & 21000 \\
\hline & \multicolumn{5}{|c|}{ After neutralization } \\
\hline Aged concentrate, fresh pulp & 237 & 109 & 3390 & 5390 & 8960 \\
Aged concentrate, aged pulp & 130 & 550 & 3320 & 5350 & 9010 \\
Washed concentrate, fresh pulp & 298 & 2070 & 1880 & 3710 & 8200 \\
Washed concentrate, aged pulp & 324 & 1760 & 2020 & 4450 & 7800 \\
\hline
\end{tabular}

case of the washed sample. Some differences in the amounts of $\mathrm{MnO}_{2}$ addition between the two samples could also have contributed to the differences in final ferric/ferrous ratios. (At pH 3.5 all ferric present in the pulp should precipitate, hence, total Fe concentration detected after neutralization in solution was due to ferrous presence).

The equilibrium adsorption isotherms generated for uranium recovery using strong-base A500 resin from the four pre-neutralized leach slurries are shown in Figure 6.

Parameters of Langmuir isotherm $\left(Y_{\mathrm{r}}={ }_{1+b X S}^{a b X s}\right)$ used to fit equilibrium data are listed in Table VIII.

Ageing of the concentrate prior to uranium leaching did not have a noticeable effect on uranium recovery by RIP. This can be attributed to the relatively low sulphide grade and addition of $\mathrm{MnO}_{2}$ during leaching (which possibly resulted in the destruction of at least part of the polythionates that might have formed during ageing).

It seems well proven that ageing of the pulp between leaching and RIP suppressed the efficiency of uranium recovery from the pulp. Sulphur was found in the caustic eluates obtained during stripping of the resin loaded from aged pulp.

\section{Conclusions}

The processing of sulphide-bearing material for uranium recovery by resin-in-pulp was found to be prone to the risk of polythionates formation by partial oxidation of sulphide minerals in the presence of oxidants such as ferric ion, manganese dioxide, and oxygen. Polythionates adversely affect uranium recovery as they are loaded more selectively than uranium by the strong-base resins that are conventionally used at uranium plants.

Polythionates could be formed during:

> Mineral processing ahead of leaching (comminution, flotation, drying)

> Acidic leaching

- Leached pulp storage and neutralization.

Possible mitigation strategies against this phenomenon include minimization of the leach duration, optimization/minimization of oxidant addition, and minimizing the ageing of pulp between the leaching, neutralization, and adsorption steps. A strategy for the destruction of polythionates will have to be developed for the

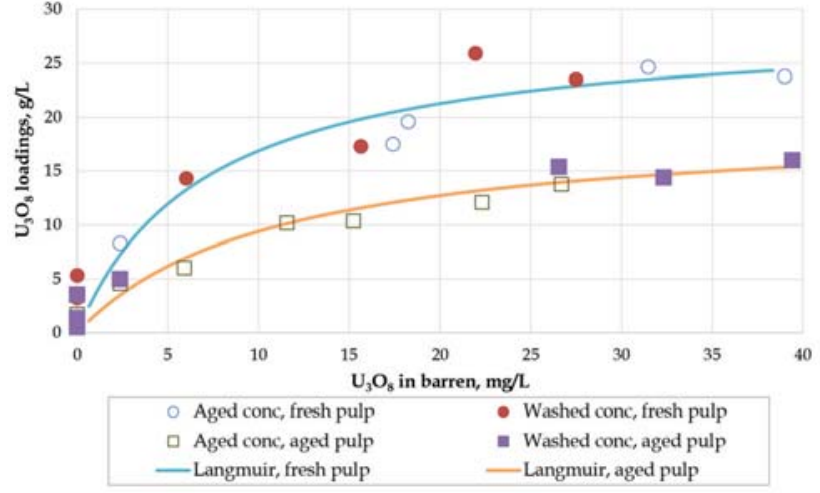

Figure 6-Uranium equilibrium data, sample 4

\section{Table VIII}

Parameters of Langmuir isotherm

\begin{tabular}{|l|c|c|}
\hline Parameter & $\boldsymbol{a}$ (maximum loading) & $\mathbf{b}$ (selectivity coefficient) \\
\hline Fresh pulp & 28.87 & 0.14 \\
Aged pulp & 19.64 & 0.09 \\
\hline
\end{tabular}

case where they do form; alternatively, resin regeneration with caustic will have to be conducted after every adsorption cycle. The topic remains under investigation at Mintek.

\section{References}

Descostes, M., Vitorge, P., and Beaucaire, C. 2004. Pyrite dissolution in acidic media. Geochimica et Cosmochimica Acta, vol. 68, no. 22. pp. 4559-4569.

Druschel, G. and BordA, M. 2006. Comment on 'Pyrite dissolution in acidic media' by M. Descostes, P. Vitorge, and C. Beaucaire. Geochimica et Cosmochimica Acta, vol. 70. pp. 5246-5250.

Druschel, G., HAMERS, R., and BANFIELD, J. 2003. Kinetics and mechanism of

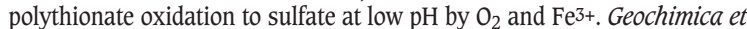
Cosmochimica Acta, vol. 67, no. 23. pp. 4457-4469.

Fleming, C., BRown, J., and BотнA, M. 2010. An economic and environmental case for re-processing gold tailings in South Africa. SGS Minerals. Technical Bulletin, March. p. 12

Lowson, R. 1982. Aqueous oxidation of pyrite by molecular oxygen. Chemical Reviews, vol. 82. pp. 461-497.

McKAY, D. and HALPERN, J. 1958. A kinetic study of the oxidation of pyrite in aqueous suspension. Transactions of the Metallurgical Society of AIME, vol. 212. pp. 301-309.

NugENT, E. 1956. The chemistry of the poisons associated with the ionexchange process. The South African Industrial Chemist, vol. 10. pp. 282-290.

OLIVERA, D. 2016. Mintek reveals new tailings retreatment process. http://www.miningweekly.com/article/mintek-reveals-new-tailingsretreatment-process-2016-12-07/rep_id:3650

Rempel, G. and ChANDA, M. 1986. Oxidation of polythionates. US patent 4582690 A.

Schippers, A. 2004. Biogeochemistry of metal sulfide oxidation in mining environments, sediments, and soils. Sulfur Biogeochemistry—Past and Present. Amend, J.,Edwards, K., and Lyons, T. (eds.). Geological Society of America, Boulder, Colorado. pp. 49-62.

Schmiedel, H. 1984. Reegenration of polythionate poisoned ion exchange resins used in uranium recovery. US patent 4486390.

VAn RenSBURG, S. and MASHABA, S. 2016. Guidelines for retreatment of SA gold tailings: MINTEK's learnings. Southern African Institute of Mining and Metallurgy, Johannesburg.

VAN TonDER, D. and KotZE, M. 2007. Uranium recovery from acid leach liquors: IX or SX? Proceedings of the ALTA Uranium Conference, Perth. ALTA Metallurgical Services, Perth.

Vongprom, Y., HAwBoldt, K., and BotTARo, C. 2008. Thiosalt stability - impact on AMD. Proceedings of the 2008 US EPA/NGWA Remediation of Abandoned Mine Lands Conference. http://ngwa.confex.com/ngwa/ mine08/recordingredirect.cgi/id/226

WooDcock, J. 1961. Some aspects of the oxidation of sulphide minerals in aqueous suspension. Proceedings of the Australasian Institute of Mining and Metallurgy, vol. 198. pp. 47-48. 